\title{
What is the requirement for out-of-hours operating in orthopaedics?
}

\author{
M. MCKEE, P. PRIEST, M. GINZLER \& N. BLACK \\ Health Services Research Unit, London School of Hygiene and Tropical Medicine, \\ Keppel Street, London WC1E 7HT
}

\section{SUMMARY}

Recent reports have emphasized the need to reduce the amount of unsupervised surgery performed at night by junior doctors. However there is little guidance about when an operation must be performed urgently and when it can be postponed safely. This study describes the existing pattern of out-of-hours trauma and orthopaedic surgery in four hospitals and reports the views of a panel of surgeons and anaesthetists on the extent to which operating could be postponed until the following day

Operations at night are uncommon - a mean of 0.6 per night and occurring on only $40 \%$ of nights - though their frequency shows two-fold variation between hospitals. With certain assumptions it is estimated that up to a third of out-ofhours operations could be postponed safely to the following day. Further evaluation is required of those operations about which the panel failed to reach agreement.

While most of the procedures undertaken at night are within the competence of a registrar, some require the direct involvement of a consultant.

\section{INTRODUCTION}

There is increasing concern about the safety of unsupervised operations performed at night by junior doctors. The Confidential Enquiry into Peri-Operative Deaths (CEPOD) (Buck et al., 1987) concluded that many operations are undertaken by surgeons who are too junior and inexperienced, and implicated inadequate supervision as a factor in $10.4 \%$ of deaths due to surgical factors. Subsequently the Royal College of Surgeons (1990) stated that for operations classified as 'urgent' in CEPOD, (such as major fractures), 'it is now acknowledged that many (of 
these) conditions are better treated during the course of a normal operating list'. Despite its importance, the CEPOD classification (emergency, urgent, scheduled and elective) is not exhaustive (Associations of Anaesthetists and Surgeons, 1989) and there is a lack of detailed guidance about which procedures can be safely postponed.

This study attempts to clarify the issue, firstly by identifying which orthopaedic and trauma operations are undertaken at night and by whom, and secondly by considering the appropriateness of such procedures being performed out-of-hours, using a consensus development method. Such methods are a way of tackling an issue where a variety of opinions exist and where published evidence is either conflicting or absent.

\section{METHODS}

Hospitals in four National Health Service districts were studied - one teaching hospital and three district general hospitals, one in inner London, one in outer London, and one approximately 50 miles from London.

Data on all operations commencing between 5 p.m. and 9 a.m. were extracted from the theatre registers or emergency theatre lists for 4 separate months during the course of $1988 / 89$. Operations which were obviously part of a routine list commencing before 9 a.m. or continuing after 5 p.m. were excluded. These quantitative data along with qualitative data obtained from interviews with junior medical staff plus a review of the literature on urgency of operating were combined in a report.

A panel was selected consisting of five consultant orthopaedic surgeons, two consultant anaesthetists and two orthopaedic registrars. A nominal group technique was used to explore the extent to which a consensus view existed regarding the appropriateness of out-of-hours surgery (Glaser, 1980). Approximately 6 weeks prior to the date of the panel meeting each participant was sent: (1) the report which had been produced in the first phase of the study; (2) a review of current concerns about the work of junior doctors including arguments for and against the exsiting system; and (3) a first round questionnaire which sought panellists' views on the safety of postponing operations in particular clinical circumstances. Only fractures requiring a general anaesthetic or regional block were considered and, to avoid misunderstandings, the terms 'complicated' (having one or more of the following features: moderate or severe displacement; neurovascular involvement; are compound; or where the skin is at risk) and 'uncomplicated' were used. The terms 'technically demanding' and 'technically undemanding' were also used in some cases, although these terms were not defined explicitly. Although the panel had been asked to consider operations performed before and after midnight, some argued that 9 p.m. would have been a more appropriate threshold, as daytime theatre staff with knowledge of specialized orthopaedic equipment are not available after this time. This might have altered the results.

The panel's responses were used to generate second round questionnaires for use in a round table discussion chaired by one of us (NB) and lasting approximately 
3 hours. After an introductory explanation, the panel discussed the items on the questionnaire. At the end of the discussion on each item, participants were asked to rate the appropriateness of postponing surgery, using a nine point scale in which 1 indicated that surgery should never be postponed and 9 indicated that it can always be postponed. There was no pressure on participants to reach consensus.

Panellists were asked to base their responses on the existing situation where most operations at night are performed by registrars, but to bear in mind the recommendations of the CEPOD report. They were also asked to disregard existing resource constraints such as non-availability of theatres the following day and to base their replies on what they believed to be good clinical practice. A record of the discussion was made.

The responses were analysed both for agreement and the appropriateness of out-of-hours surgery. Agreement was deemed to be present when after discarding the single highest and lowest scores, the remaining scores all lay within a three point range. Disagreement occurred when, after discarding the single highest and lowest scores, at least one of the remaining seven scores was 1-3 and at least one was 7-9. All other results were designated as partial agreement. The rationale for this scoring system has been described elsewhere (Scott \& Black, 1991).

\section{RESULTS}

Table 1 shows the amount of out-of-hours operating in the four hospitals. The mean number of operations per night varied by more than two-fold from 0.38 in Hospital C to 0.86 in Hospital A.

The frequency of night time operations also varies. In Hospital A procedures were undertaken on $52 \%$ of nights whereas in Hospital $C$ they took place on only $27 \%$ of nights. For Hospitals A, B and C, the frequency of night-time operations was related to the total volume of work undertaken by the hospital, with four to five night-time operations per hundred deaths and discharges. However in Hospital D only 2.4 procedures per hundred deaths and discharges occurred.

The principal operations carried out at night are shown in Table 2. Treatment of fractures accounted for $72 \%$ of procedures. The most common single procedure

Table 1. Clinical activity in trauma and orthopaedics in the four study hospitals

\begin{tabular}{|c|c|c|c|c|c|c|c|c|c|}
\hline \multirow[b]{2}{*}{ Hospital } & \multirow{2}{*}{$\begin{array}{c}\text { Deaths \& } \\
\text { discharges } \\
\text { per year }\end{array}$} & \multirow{2}{*}{$\begin{array}{l}\text { Night-time } \\
\text { operations } \\
4 \text { months }\end{array}$} & \multirow{2}{*}{$\begin{array}{l}\text { Mean no. of } \\
\text { operations } \\
\text { per night }\end{array}$} & \multicolumn{5}{|c|}{$\begin{array}{l}\text { Number of night-time } \\
\text { operations }\end{array}$} & \multirow{2}{*}{$\begin{array}{l}\text { No. of night-time } \\
\text { operations per } 100 \\
\text { deaths \& discharges }\end{array}$} \\
\hline & & & & 0 & 1 & 2 & 3 & 4 & \\
\hline A & 2100 & 103 & 0.86 & 58 & 36 & 19 & 7 & 2 & 4.9 \\
\hline B & 1600 & 73 & 0.61 & 69 & 37 & 13 & 2 & 1 & 4.6 \\
\hline C & 1100 & 45 & 0.38 & 87 & 27 & 6 & 2 & 0 & 4.1 \\
\hline D & 2400 & 58 & 0.48 & 81 & 29 & 9 & 1 & 2 & 2.4 \\
\hline All & 7200 & 279 & 0.58 & 295 & 129 & 47 & 12 & 5 & 3.8 \\
\hline
\end{tabular}




\section{M. McKee et al.}

Table 2. Number of orthopaedic operations (\%) carried out betweeen 5 p.m. and 9 a.m. during 4 months in the study hospitals

\begin{tabular}{|c|c|c|c|c|c|}
\hline \multirow[b]{2}{*}{ Operation } & \multicolumn{4}{|c|}{ Hospital } & \multirow[b]{2}{*}{ All hospitals } \\
\hline & A & B & C & $\mathrm{D}$ & \\
\hline \multicolumn{6}{|l|}{$\begin{array}{l}\text { Fractures } \\
\text { internal fixation }\end{array}$} \\
\hline Shaft of femur & & $2(3)$ & & & $2(1)$ \\
\hline Neck of femur & $13(13)$ & $8(11)$ & $2(4)$ & $6(10)$ & $29(10)$ \\
\hline Total hip replacement & $9(9)$ & $1(1)$ & $5(11)$ & $2(3)$ & $17(6)$ \\
\hline Knee & & $3(6)$ & $1(2)$ & & $4(1)$ \\
\hline Ankle & $12(12)$ & $6(8)$ & $3(7)$ & $5(9)$ & $26(9)$ \\
\hline Elbow & $7(7)$ & $3(4)$ & $2(4)$ & $5(9)$ & $17(6)$ \\
\hline Hand & $2(2)$ & $1(1)$ & $1(2)$ & $2(3)$ & $6(2)$ \\
\hline Sub-total & $43(43)$ & $24(33)$ & $14(31)$ & $20(34)$ & $101(36)$ \\
\hline \multicolumn{6}{|l|}{$\begin{array}{l}\text { Manipulation } \\
\text { under anaesthetic }\end{array}$} \\
\hline Humerus & & $3(4)$ & & $1(2)$ & $5(2)$ \\
\hline Colles fracture & $28(27)$ & $16(22)$ & $10(22)$ & $17(29)$ & $71(25)$ \\
\hline Finger & & & $1(2)$ & & $1(1)$ \\
\hline Foot & $4(4)$ & $9(12)$ & $1(2)$ & $3(5)$ & $17(6)$ \\
\hline Hip (post-THR) & $1(1)$ & & & $2(3)$ & $1(1)$ \\
\hline Sub-total & $33(32)$ & $28(38)$ & $12(27)$ & $23(40)$ & $94(34)$ \\
\hline \multicolumn{6}{|l|}{ External fixation } \\
\hline Ankle & & & & $1(1)$ & $1(1)$ \\
\hline Removal ext. fixator & $3(3)$ & & $1(2)$ & & $4(1)$ \\
\hline Sub-total & $3(3)$ & & $1(2)$ & $1(1)$ & $5(2)$ \\
\hline \multicolumn{6}{|l|}{ Examination of knee } \\
\hline Arthroscopy & $6(6)$ & $2(3)$ & & & $8(3)$ \\
\hline EUA & $2(2)$ & & & & $2(1)$ \\
\hline Sub-total & $8(8)$ & $2(3)$ & & & $10(4)$ \\
\hline \multicolumn{6}{|l|}{ Soft tissue injuries } \\
\hline Debride wound & $6(6)$ & $5(7)$ & $1(2)$ & $4(7)$ & $16(6)$ \\
\hline Repair tendons & $8(8)$ & $6(8)$ & $7(15)$ & $2(3)$ & $23(8)$ \\
\hline Suture laceration & & $5(7)$ & $5(11)$ & & $10(4)$ \\
\hline Sub-total & $14(14)$ & $16(22)$ & $13(29)$ & $6(10)$ & $49(18)$ \\
\hline \multicolumn{6}{|l|}{ Others } \\
\hline Wire mandible & & & & $3(5)$ & $3(1)$ \\
\hline Insert ICP screw & & & & $1(2)$ & $1(1)$ \\
\hline Apply skull traction & $1(1)$ & & & & $1(1)$ \\
\hline Insert Steinman's pin & $1(1)$ & & $5(11)$ & $1(2)$ & $7(3)$ \\
\hline Perform bone graft & & & & $1(2)$ & $1(1)$ \\
\hline Amputate digit & & $3(4)$ & & $2(3)$ & $5(2)$ \\
\hline Sub-total & $2(2)$ & $3(4)$ & $5(11)$ & $8(12)$ & $18(7)$ \\
\hline Total & $103(100)$ & $73(100)$ & $45(100)$ & $58(100)$ & 279 (100) \\
\hline
\end{tabular}

Notes: ICP - Intra-cranial pressure Source: Theatre registers and SH3 statistics

is manipulation of Colles fracture, representing $25 \%$ of all out-of-hours procedures. This is followed by operations for fractured neck of femur (including total hip replacement) and internal fixation of fractured ankles.

The contribution of particular procedures to total workload varies considerably between hospitals. Operations for fractured neck of femur form a greater proportion 
of the total in Hospital A than elsewhere, and patients appear more likely to undergo total hip replacement rather than pinning in Hospital $\mathrm{C}$ compared with the other hospitals. Treatment of soft tissue injuries represent a greater proportion of out-of-hours operations at Hospital $C$ than in the other hospitals.

Orthopaedic procedures rarely begin after midnight (Fig. 1). Of those that did, the most common were reduction of Colles fractures (nine), internal fixation of ankle fractures (four), and repair of tendons (three).

The conclusions of the panel about postponing surgery are summarised in Tables 3-5. The main reasons for these views became clear during the panel discussion. The key points regarding the commonest injuries were as follows:

(1) the panel disagreed about reducing Colles fractures after midnight. Although most would reduce all such cases as soon as possible, one panellist would postpone treatment. Delays due to the lack of availability of an anaesthetist can be avoided by using a regional anaesthetic block;

(2) most fractures of the elbow should be operated on without delay, although cases seen after midnight which are technically demanding but otherwise uncomplicated should often be postponed for a consultant opinion the following day. Disagreement about postponing some cases seen after midnight reflected some views that surgery could be postponed for perhaps four hours but not eight. Discussion was complicated by the wide variation in complexity of fractures, ranging from a fractured olecranon process to a supra-condylar fracture with multiple fragments;

(3) surgery for supra-condylar fractures in children should not be postponed, although one panellist suggested treating them with traction for several days rather than performing early surgery.

(4) fractures of the malleoli with complications or severe displacement should receive initial treatment at night. In particular, a case of severe displacement could often be reduced considerably pending subsequent definitive treatment.

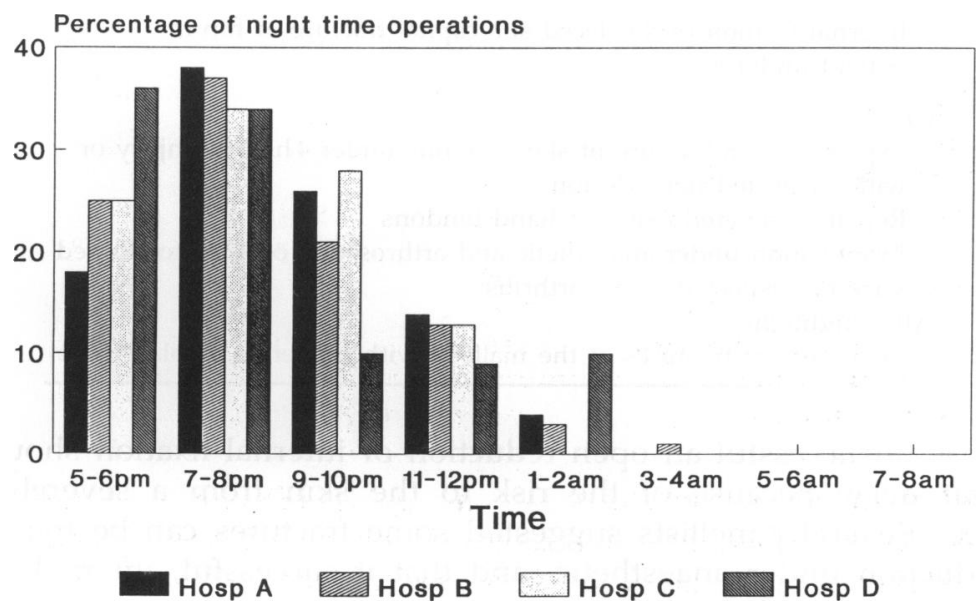

Fig. 1. Percentage of operations started in each 2-h period. 
Table 3. Orthopaedic operations which it is usually not appropriate to postpone

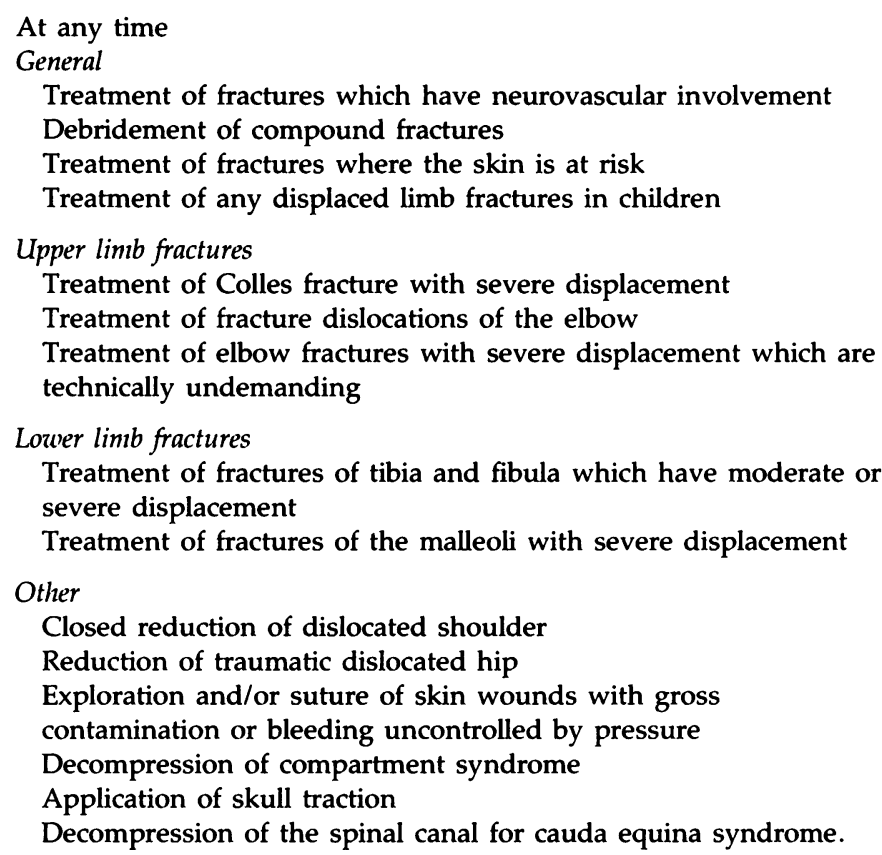

Before midnight

Upper limb fractures

Treatment of uncomplicated Colles fracture

Treatment of elbow fractures with moderate displacement or with severe displacement which is technically demanding

Lower limb fractures

Treatment of fractures of tibia and fibula which are uncomplicated with no displacement Internal fixation of displaced sub-capital fracture of hip in patient under 65

Other

Exploration and suture of skin wounds under $4 \mathrm{~h}$ since injury or with suspected nerve lesion

Repair of severed extensor hand tendons

Examination under anaesthetic and arthroscopy of knee for locked

knee or suspected septic arthritis

After midnight

Treatment of fractures of the malleoli with moderate displacement

If this is unsuccessful an open reduction or internal fixation should proceed without delay because of the risk to the skin from a severely displaced fracture. Several panellists suggested some fractures can be treated initially by reduction under anaesthetic, and that if successful, internal fixation can be postponed until the following day;

(5) the panel considered definitive repair of severed flexor and extensor tendons. 
Table 4. Orthopaedic operations which it is not normally appropriate to undertake at night

At any time

Examination under anaesthetic and arthroscopy for acute

haemarthrosis of the knee

After midnight

Treatment of uncomplicated elbow fractures with moderate displacement which are technically undemanding

Internal fixation of fractured neck of femur, except in patients under 65 with displaced sub-capital fractures

Examination under anaesthetic and arthroscopy for locked knee Repair of severed hand tendons

Table 5. Orthopaedic operations where there is disagreement about the appropriateness of operating at night

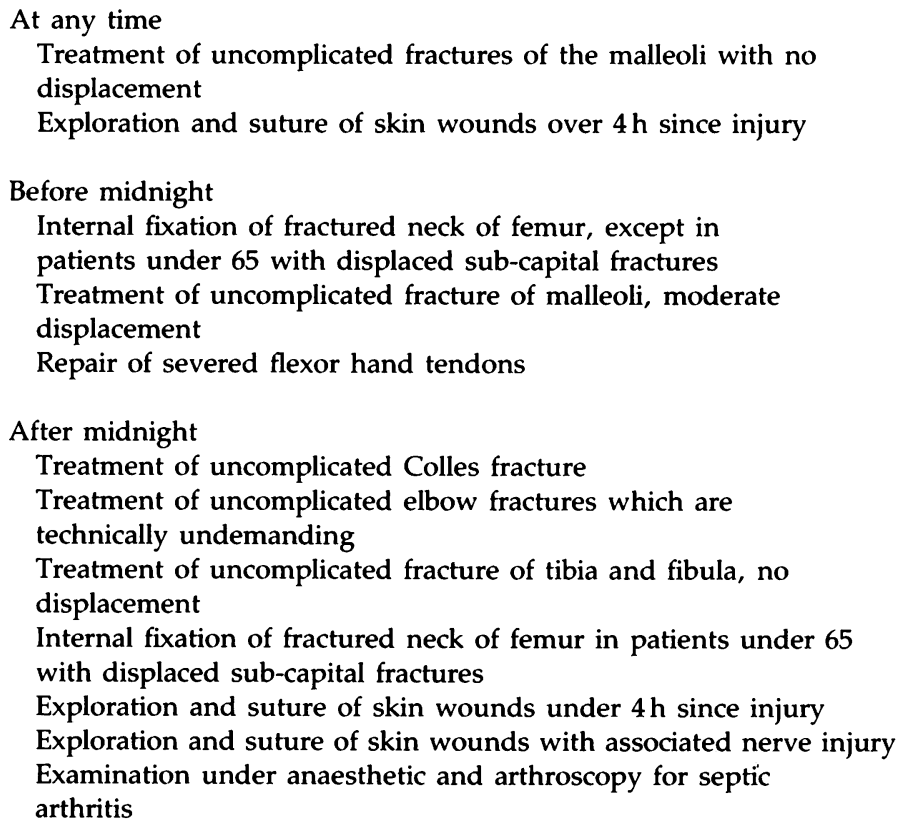

They agreed that immobilisation with dressing of the wound should not be delayed. Several panellists expressed the view that flexor tendons should only be repaired by a skilled surgeon during a routine operating list. In practice the timing of surgery is often dictated by the circumstances as many patients with tendon injuries are admitted at night when drunk. It is inappropriate to anaesthetise such cases, and the diagnosis is often not made until the following day.

(6) in disagreeing about the postponement of treatment of fractured neck of femur seen after midnight, the panel suggested that there was a need for 
more research on the safe length of delay prior to surgery in such cases and;

(7) in most circumstances repair of skin wounds requiring the facilities of an operating theatre should not be postponed if seen before midnight. However panellists disagreed about treatment of such cases if seen after midnight, unless there was gross contamination of the wound or bleeding uncontrolled by pressure.

During the discussion the panel also considered which procedures should be undertaken by a registrar. This was complicated by the varied experience of registrars and the difficulty in generalising about injuries. Consultant involvement was thought to be required in cases of major trauma and when the decision is made to amputate a limb or perform a total hip replacement. A registrar should rarely apply skull traction without supervision. Thus most procedures currently undertaken are thought to be within the competence of a typical registrar.

\section{DISCUSSION}

This study represents a first step towards clarifying the issue of which operations may be postponed safely, and thus helps to explore ways in which out-of-hours orthopaedic workload might be altered when the number of junior doctors is reduced as a result of Achieving a Balance (DHSS, 1986). Factors influencing the level of out-of-hours operating include the availability of surgeons, anaethetists and theatres, and clinical judgement. The relatively low proportion of cases undergoing night time surgery in Hospital D may be due to the lack of availability of a surgeon, as registrars covering this hospital also cover hospitals in two other districts when on call. Thus on two nights out of three the duty registrar may have to travel a considerable distance to the hospital. The influence of clinical judgement is evidenced by the differing proportion of patients with fractured neck of femur who undergo a total hip replacement at night.

The reasons for night-time operating are complex, but two factors contribute: (1) night-time surgery is often undertaken to relieve pain rather than to prevent further deterioration and (2) because of non-availability of staff or theatres during the day. However, these factors do not explain all the variation in operating between our study hospitals. As the panellists' opinions demonstrated there are genuine differences of opinion as to the appropriateness of night-time surgery. This is supported by views expressed in interviews and in the published literature. There is little to guide decision making about postponement of surgery, despite the view expressed in CEPOD that some operations may be performed more safely on a routine list. Even when studies have been performed, the results are often inconclusive. For example, two recent studies of the effect of timing of surgery on outcome of fractured neck of femur have produced conflicting results (Davis et al., 1988; Villar et al., 1986).

The conclusions of the panel can only be regarded as guidelines, and not rigid protocols. In each case the needs of the individual patient must be taken into account, including not only the patient's clinical condition, but also the expertise and the alertness of the surgeon performing the operation. 
Can the number of operations performed at night be reduced? Unlike general surgery or gynaecology, the potential for reduction is limited by the relatively small number which take place, and the very few which commence after midnight. Information was not available on the indications for surgery for each patient in the first part of the study, thus precluding calculation of the number of operations which could be postponed. Our best estimate is that up to $30 \%$ of operations could be postponed, including almost all of those taking place after midnight. The principal condition which would be affected by a postponement of night-time surgery is fractured neck of femur. The practicalities of doing this can be overcome by introduction of a daily trauma list (I. Hamilton, personal communication). However fractured neck of femur represents less than $15 \%$ of all out-of-hours orthopaedic operations and a daily trauma list requires staff to be available without other commitments each morning to avoid having to cancel routine lists.

In conclusion, there is a need for night-time operations in orthopaedic surgery. However some operations currently done at night could be postponed and the number which must be done at night is small.

\section{ACKNOWLEDGEMENTS}

We are grateful to the participants in the panel: Dr R. C. Birt, Mr J. P. S. England, Mr C. J. Good, Mr I. Hamilton, Mr A. M. Jackson, Mr O. A. Jamall, Prof D. F. Paton, Mr P. J. Verrill, Mr L. Wilson; to the theatre staff and junior medical staff of the hospitals concerned; and to Mr Duncan Hunter for helpful comments on an earlier draft. This work received financial support from the Department of Health. The views expressed are those of the authors alone.

\section{REFERENCES}

Association of Anaesthetists of Great Britain and Ireland and Association of Surgeons of Great Britain and Ireland (1989) Efficiency of theatre services. London, Association of Anaesthetists of Great Britain and Ireland, Association of Surgeons of Great Britain and Ireland 18.

Buck N., Devlin H. B. \& Lunn J. N. (1987) The Report of a Confidential Enquiry into Perioperative Deaths. Nuffield Provincial Hospitals Trust/Kings Fund, London.

Davis T. R. C., Sher J. L., Porter B. B. et al. (1988) The timing of surgery for intertrochanteric femoral fractures. Injury 19, 244.

Department of Health and Social Security (DHSS) (1986) Hospital Medical Staffing: Achieving a Balance. HMSO, London.

Glaser E. M. (1980) Using behavioural science strategies for defining the state-of-the-art. Journal of Applied Behavioural Science 16, 79.

Royal College of Surgeons of England (1990) Commission on the provision of surgical services. Consultant Responsibility in Invasive Surgical Procedures. The Royal College of Surgeons of England, London.

Scott E. A. \& Black N. A. (1991) When does consensus exist in expert panels? Journal of Public Health Medicine 13, 35.

Villar R. N., Allen S. M. \& Barnes S. J. (1986) Hip fractures in healthy patients: operative delay versus prognosis. British Medicine Journal 293, 1203. 